\title{
Alterations in the microhardness of a titanium alloy affected to a series of nanosecond laser pulses
}

\author{
Ivan Ushakov ${ }^{1,2, *}$ and Yuri Simonov ${ }^{1}$ \\ ${ }^{1}$ National University of Science and Technology «MISIS», Leninsky avenue, 4, Moscow, \\ 119049, Russian Federation \\ ${ }^{2}$ Moscow Aviation Institute (National Research University), Volokolamskoe highway, 4, Moscow, \\ 125993, Russian Federation
}

\begin{abstract}
The alterations in the microhardness of a titanium alloy $\mathrm{Ti}_{85.85} \mathrm{Al}_{6.5} \mathrm{Zr}_{4} \mathrm{Sn}_{2} \mathrm{Nb}_{1} \mathrm{Mo}_{0.5} \mathrm{Si}_{0.15}$ subjected to laser treatment were investigated. Laser processing consists of a series of pulses with durations 20 ns. We used various methods of laser processing, which differed in power density, wavelength, geometrical pattern of irradiation and so on. The dependences of the microhardness on the load on the indenter were found. The laser processing modes providing the increased microhardness are determined. The investigations were carried out at loads from $0.49 \mathrm{~N}$ to $4.9 \mathrm{~N}$, with maximum indentation depth of the Vickers pyramid up to $12 \mu \mathrm{m}$. Vickers microhardness can be increased by $20-40 \%$. At the same time, the plastic properties of the hardened layer are improved. The probability of crack formation during indentation of the initial alloy increased with a load on the indenter and reached 0.52 for a load of $4.9 \mathrm{~N}$. In two of the treated areas of the three presented, crack formation was not recorded at any load. The mechanisms of hardening of the material surface layer under the influence of a laser pulse are discussed. Using the methods of computational mathematics, the character of sample heating under the influence of a single laser pulse is determined. The perspectives for the development of the proposed processing method are permitting to obtain the optimal mechanical properties of the hardened layer are discussed.
\end{abstract}

\section{Introduction}

The work of aircraft gas turbine engine parts occurs in harsh conditions and is accompanied by intense wear. The blades of gas turbine engines are usually made of metal alloys, in particular titanium alloys. One of the ways to increase their wear resistance is associated with hardening of the surface layer. Various hardening technologies have been developed for surface layers of parts [1-3]. These technologies are aimed at increasing the surface microhardness, creating compressive stresses, increasing toughness, etc.

In this case, both the depth of the hardened layer and its adhesion to the main material are of great importance. During the operation both the surface and the volume of material

\footnotetext{
* Corresponding author: ushakoviv@mail.ru
} 
are subjected to mechanical loads. The properties of the hardened layer should be free of cracking occurring at the boundary between the hardened material and the initial one.

Many methods have been developed to increase the complex of mechanical properties of metal alloys: spraying, laser additive technologies, shot blasting, laser peeing, plasmaelectrolytic processing, etc. [4-6]. Some of these techniques are actively used in practice, and some types of processing are very difficult to implement in real production [7-9]. For example, the technology for using high-current pulsed electron beams is quite expensive and complicated for technical implementation [10].

The successes achieved in hardening the surface of titanium alloys are impressive. At the same time, new surface hardening technologies, as a rule, do not give a significant advantage over existing ones. A number of researchers believe that in future it will be advisable to include composite compounds [7, 11].

However, metal alloys are currently the main materials from which the blades of gas turbine engines are made. In this case there is a need for further improvement of hardening technologies for titanium parts of gas turbine engines. The main tasks for the development of technologies for the formation of surface properties of titanium alloy are following: it is necessary to increase the microhardness of the surface layer of a titanium alloy, as well as its plastic properties, wear resistance, and corrosion resistance. The surface layer should be sufficiently smooth, should have sufficient thickness and good adhesion to the initial material. In addition, the technology should be cheap, well reproducible in practice and have a high processing speed.

It should be noted that over the past decades technologies for laser processing of materials have received great development [1, 4, 12]. This is due not only to the investigation of the physicochemical processes of the action of laser radiation on matter, but also to the development of laser technology. Over the past decades, it has been possible to increase the efficiency of laser systems significantly. Their reliability has increased. Significant success was achieved in the formation of the required parameters of laser pulses: pulse duration, power density, energy distribution in the irradiation region, etc. Accurate and reliable positioning systems for the parts processed by laser radiation were developed.

The aim of this work is the experimental identification of the dependences of the microhardness on the load for various laser treatment modes, as well as determining the parameters of the laser processing, which provide a simultaneous increase in microhardness and crack resistance of the hardened surface layer.

\section{Experimental procedure}

Mechanical tests were performed on a titanium alloy $\mathrm{Ti}_{85.85} \mathrm{Al}_{6.5} \mathrm{Zr}_{4} \mathrm{Sn}_{2} \mathrm{Nb}_{1} \mathrm{Mo}_{0.5} \mathrm{Si}_{0.15}$.

The surface of the material was treated by a series of nanosecond pulses. The following equipment was used: laser systems ELS-01 and ELS-03. The duration of the laser pulses is approximately 20 nanoseconds. The differences between these installations are following: 1) ELS-01 $\lambda=1064 \mathrm{~nm}, \mathrm{E}=50-100 \mathrm{~mJ}, v=1-50 \mathrm{~Hz}$; 2) ELS-03 $\lambda=532 \mathrm{~nm}, \mathrm{E}=15-$ $20 \mathrm{~mJ}, v=1-100 \mathrm{~Hz}$.

The material was processed according to three modes.

1. The first mode (laser ELS-03). The formation of the irradiated zones (square or rectangular) was ensured by moving the sample in the " $x$ " and " $y$ " directions. The matrix of irradiated rounded areas was formed during the first stage (Figure 1a). This matrix consists of non-overlapping laser processing areas. The power density varied from $0.5 \times 10^{12} \mathrm{~W} / \mathrm{m}^{2}$ to $90 \times 10^{12} \mathrm{~W} / \mathrm{m}^{2}$. The second matrix was formed during the second stage (Figure $1 \mathrm{~b}$ ). The first and second matrixes do not overlap. Subsequent processing stages include the formation of additional matrices of irradiated areas displaced relative to the first two ones 
(Figure 1c, 1d). They complete overlap of the irradiated areas. The processing described above was repeated from 2 to 5 times. The dimensions of the diameters of the irradiated areas could determine and change during the transition to the next treatment cycle.

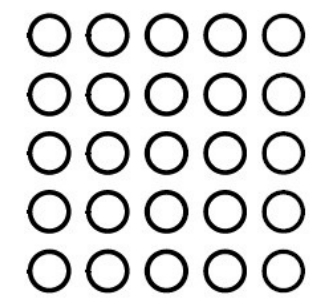

a)

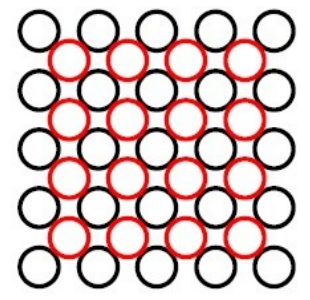

b)

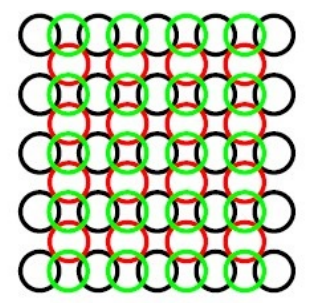

c)

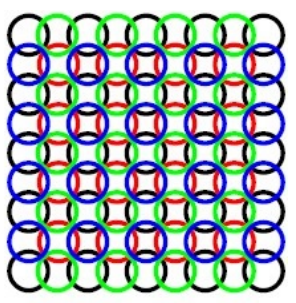

d)

Fig. 1. The sequence diagram of the irradiation of surface is following: a) the first stage; b) the second stage; c) the third stage; d) the fourth stage

2. The second mode (laser ELS-03). The surface was irradiated by laser pulses of a certain diameter (for example diameter was $1 \mathrm{~mm}$ ). The sample was moved to $15 \mathrm{~mm}$ in the " $x$ " direction with constant speed of $185 \mathrm{~mm} / \mathrm{s}$. The pulse repetition rate is $100 \mathrm{~Hz}$. Then the sample was displaced to $0.6-0.9 \mathrm{~mm}$ in the "y" direction and so on. Processing was continued until formation of an irradiation area with a size of $15 \times 15 \mathrm{~mm}$.

3. The third mode (laser ELS-01). The third processing mode is similar to the second one. Differences are following: 1) the laser unit ELS-01 was used; 2) a laser pulse repetition rate was of $50 \mathrm{~Hz}$; 3) the displacement in the "y" direction of was $50 \mu \mathrm{m}$.

The surface of the material was tested by Vickers pyramid after laser treatment. The standard and modernized methods of testing were used [13]. The PMT-3M microhardness tester was used.

\section{Experimental results and discussion}

Three types of laser treated zones were formed in accordance with the three modes of laser irradiation. The surface of each area has its own significant features.

There aren't cracks in the first and second areas of treatment. The third area contains a dense network of microcracks. Such microcracks are initiated when the material was rapidly cooled. The third region has significant irregularities in the form of ditches and depressions. They are stretched along the laser processing lines (Figure 2). The third mode of treatment isn't effective, as the surface has roughness and a dense network of microcracks.

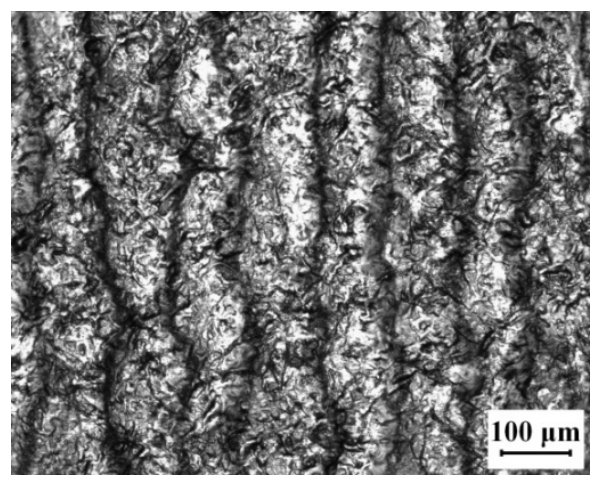

Fig. 2. The surface was treated according to the third mode. There are many microcracks and surface roughness in the area 
Microhardness was revealed by Vickers method. Several series of mechanical tests were made. Each experimental point corresponds to 20 tests. Varying the magnitude of the load during microindentation allows evaluating the depth of the treated layer. Thus, tests were made using a load from $0.49 \mathrm{~N}$ to $4.9 \mathrm{~N}$.

The probability of cracking during indentation on the untreated surface was determined experimentally. The probability of cracking during indentation by the Vickers pyramid increases from $0.2(20 \%)$ at $\mathrm{F}=0.49 \mathrm{~N}$ to almost $0.52(52 \%)$ at $\mathrm{F}=4.9 \mathrm{~N}$.

Cracks weren't detected after indentation in zones treated by modes No. 1 and No. 2. Cracks were detected after testing the zone treated according to mode No. 3.

Figure 3 shows the results of measurements of microhardness. The dependence of the microhardness on the load practically coincides with dependences No. 3 and No. 4. Dependence No. 4 is corresponded to initial material. Laser processing according to the third mode doesn't provide a significant increase of microhardness.

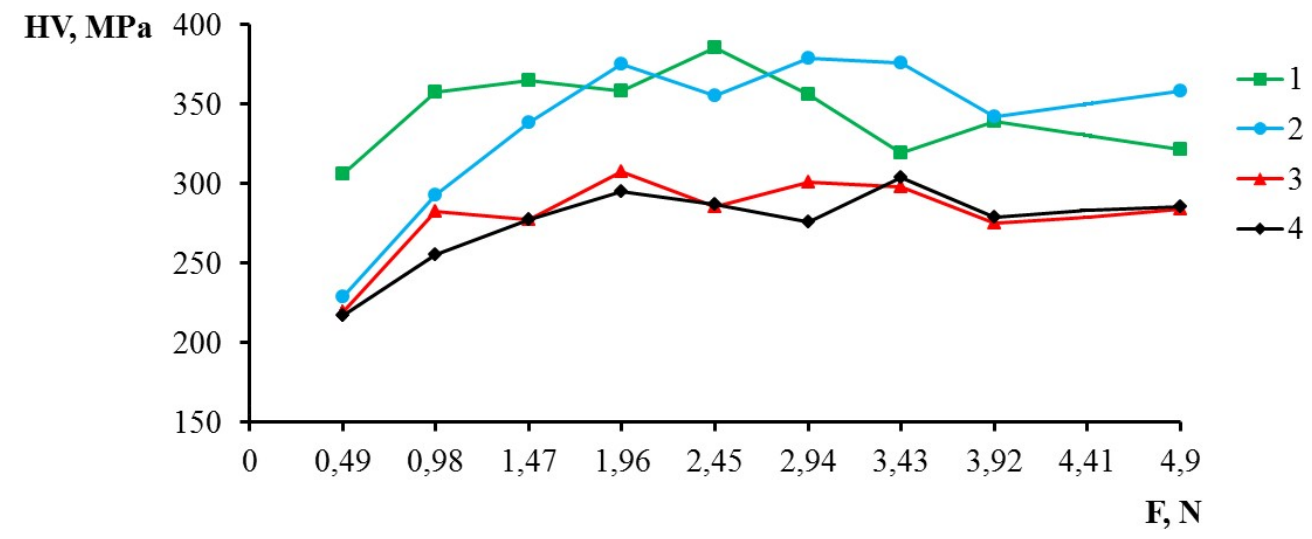

Fig. 3. Dependences of microhardness on load during indentation are shown. Dependences 1, 2, 3 correspond to laser treatment modes number 1, 2, 3. Dependence number 4 corresponds to initial material

The values of microhardness practically coincide for dependences number 2, 3 and 4 in first experimental point $(\mathrm{F}=0.49 \mathrm{~N})$. The microhardness value is almost in 1.5 times higher for the first dependence.

Dependencies No. 1 and No. 2 demonstrate a significant increase in microhardness. The microhardness for most of the experimental points of these dependences is approximately for 25 - $40 \%$ higher in comparison with untreated material.

The microhardness is significantly higher for dependence No. 1. The microhardness is higher for both minimum loads and maximal ones. High microhardness at low loads indicates to significant hardening of the surface layer. A significant decrease of microhardness at a load of $3.43 \mathrm{~N}$ or more is detected.

For dependence No. 2, the microhardness almost linearly increases from $229 \mathrm{MPa}$ to $375 \mathrm{MPa}$ with increasing of load from $0.49 \mathrm{~N}$ to $1.96 \mathrm{~N}$. With a further increase in load, the microhardness does not significantly decrease.

The parameters of the used laser irradiation modes make it possible to create a quasistable gas-plasma torch. Such a torch more or less effectively creates a protective atmosphere. However, titanium oxides and nitrides are present in the surface layer. They may be responsible for increasing the microhardness of the surface layers. In this case, the microhardness values for dependences No. 1 - 3 should be approximately the same. Significantly higher microhardness for load of $0.49 \mathrm{~N}$ indicates the influence of the heating and cooling modes of the material on the microhardness of the surface layer. 
The thickness of the treated layer was evaluated only indirectly. The indentation depth was about $12 \mu \mathrm{m}$ at the maximum load of $4.9 \mathrm{~N}$. We have to take into account the elasticplastic recovery of the material after indentation. Real depth will be significantly more than $12 \mu \mathrm{m}$. Thus, the thickness of the modified layer cannot be less than $12 \mu \mathrm{m}$.

There're several mechanisms responsible for alterations in the microhardness. As a result of ultrafast melting and subsequent cooling of the metal, surface amorphization is possible. There is a process of evaporation of the surface layer in the area of exposure. A shock wave with a shock pressure of up to $10^{10} \mathrm{~Pa}$ is formed. In this case, one should expect strain hardening of the material. Chemical reactions with the formation of solid compounds are possible. Processes of heating and annealing are possible in the case of processing according to modes No. 2 and No. 3. The thermal field can stimulate stress relaxation processes.

Clarification of priority mechanisms requires additional experiments and calculations. In this work, we simulated a thermal field under the influence of a single pulse. Note that the lifetime of the plasma torch is approximately $200 \mathrm{~ns}$. After approximately $200 \mathrm{~ns}$, the laser plasma is scattered and the upper layers of the sample begin to cool due to heat exchange with the environment and heating of the "deep" layers of the sample.

This task was solved using computer and mathematics modeling [14-16]:

$$
\frac{\partial}{\partial t}\left(\rho c_{v} T\right)=\frac{\partial}{\partial x}\left(\lambda \frac{\partial T}{\partial x}\right)+\frac{\partial}{\partial y}\left(\lambda \frac{\partial T}{\partial y}\right)+\frac{\partial}{\partial z}\left(\lambda \frac{\partial T}{\partial z}\right)+F
$$

where $\rho$ is the density of the medium; $c_{v}$ is the heat capacity of the medium at a constant volume $\mathrm{V} ; \mathrm{T}=\mathrm{T}(\mathrm{x}, \mathrm{y}, \mathrm{z})$ is the temperature; $\mathrm{x}, \mathrm{y}, \mathrm{z}$ - coordinates; $\mathrm{t}$ is time; $\lambda$ is the coefficient of thermal conductivity; $\mathrm{F}=\mathrm{F}(\mathrm{x}, \mathrm{y}, \mathrm{z})$ is the given density of heat sources. The quantities $\rho, \mathrm{c}_{v}, \lambda$ depend on the coordinates and, generally speaking, on $\mathrm{T}$.

The isotherms corresponding to the edge of the heating region are shown in Figure 4. The temperature below the center of the treatment region rises faster. At a depth of $30 \mu \mathrm{m}$ after the tenth pulse (second mode of treatment), after $1 \mathrm{~ms}$ the temperature is $\approx 500 \mathrm{~K}$, and after $25 \mathrm{~ms}$ temperature is $\approx 350 \mathrm{~K}$. Computer simulation data were previously experimentally verified on thin metal films with $30 \mu \mathrm{m}$ thickness.

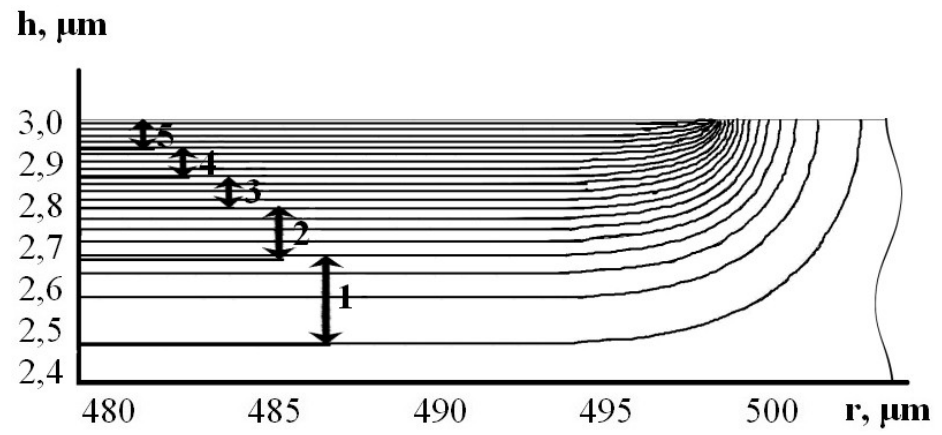

Fig. 4. There are temperature distribution under the influence of laser radiation and plasma on the surface of the sample. $R$ is the distance from the boundary of the heating region, $h$ is the depth of heating): 1 - 700-300 K, 2 - 1200-700 K, 3 - 1700-1200 K, 4 - 2300-1700 K, 5 - 2850-2300 K

The presented data of computer simulation do not take into account changes in the temperature of the sample during long laser processing. However, the results obtained suggest the influence of the thermal field on the relaxation of mechanical stresses for the second and third processing modes.

The results should be evaluated according to several criteria. The optimal technics of treatment must be a relatively simple, cheap and reproducible. Modes No. 1 and No. 2 
correspond to these criteria. Laser processing does not imply any additional procedures. A protective atmosphere, paint and liquid are not required (such for laser peeing). The proposed method has perspective for development. In particular, it is possible to modernize and combine processing modes according to modes No. 1 and No. 2.

\section{Conclusion}

A method is proposed for treating the surface of a titanium alloy $\mathrm{Ti}_{85.85} \mathrm{Al}_{6.5} \mathrm{Zr}_{4} \mathrm{Sn}_{2} \mathrm{Nb}_{1} \mathrm{Mo}_{0.5} \mathrm{Si}_{0.15}$ with a series of nanosecond laser pulses with a pulse repetition rate of $50 \mathrm{~Hz}$ and $100 \mathrm{~Hz}$. As a result of processing, it is possible to increase the microhardness of the alloy surface by $25-40 \%$.

The character of the dependence of microhardness on the load on the indenter is established, allowing to determine the value of microhardness on the surface and approximately estimate the depth of the treated layer. The increase in microhardness after treatment is recorded up to a load of $\mathrm{F}=4.9 \mathrm{~N}$, which corresponds to an indentation depth of $10-12 \mu \mathrm{m}$.

The formation of surface properties is due to the simultaneous influence of strain hardening and thermal annealing of the surface layers of the material.

An increase in microhardness is accompanied by an increase in resistance to cracking. On an untreated surface, the probability of cracking is almost 0.52 at $\mathrm{F}=0.49 \mathrm{~N}$. In the laser-treated areas (processing modes No. 1 and No. 2), the formation of fractures during indentation was not observed.

The proposed laser processing method is based only on the usage of laser radiation and an electronic-mechanical system of precise movement. Thus, no additional equipment and materials are required. This ensures a relatively low cost and simplicity of the method of processing the mechanical properties of the surface layer.

The considered method has development prospects associated with a combination of processing modes according to methods No. 1 and No. 2, and the selection of optimal parameters of laser radiation.

\section{References}

1. V.V. Girzhon and A.V. Ovchinnikov, Application of laser treatment for hardening parts of gas turbine engines from titanium alloys, Metal Science and Heat Treatment, v. 58(11-12), pp. 719-723 (2017)

2. V.N. Duradji, D.E. Kaputkin and A.Y. Duradji, Electrolyte-Plasma Modification of Surface of Ti-Based Alloy during Electrohydrodynamic Mode of Anodic Process, Journal of The Electrochemical Society, v. 164, pp. E226-E232 (2017)

3. V.A. Shulov, A.N. Gromov, D.A. Teryaev, and V.I. Engel'ko, Application of highcurrent pulsed electron beams for modifying the surface of gas-turbine engine blades, Russian Journal of Non-Ferrous Metals, v. 57(3), pp. 256-265 (2016)

4. J. Bonse, R. Koter, M. Hartelt, D. Spaltmann, S. Pentzien, S. Hohm, A. Rosenfeld, J. Kruger, Femtosecond laser-induced periodic surface structures on steel and titanium alloy for tribological applications, Applied Physics A: Materials Science \& Processing, v. 117, pp. 103-110 (2014)

5. B. Lu, D. Wang, L. Xiao, F. Li, J. Ren, L. Li and W. Wu, Microstructure Analysis of Laser Remelting for Thermal Barrier Coatings on the Surface of Titanium Alloy, MATEC Web of Conferences, v. 67, 04019 (2016) 
6. V.P. Stroshkov and I.G. Grigorov, Study of the Surface Microrelief of the Titanium VT18u Alloy after Electrochemical Dimensional Processing, Journal of Surface Investigation. X-ray, Synchrotron and Neutron Techniques, v. 4(1), pp. 81-86 (2010)

7. Y. Zhou, Y. Ding, Oxidation resistance of co-deposited Ni-SiC nanocomposite coating, Transactions of Nonferrous Metals Society of China, v. 17, pp. 925-928 (2007)

8. H. Choi, M. Jones, H. Konishi, X. Li, Effect of Combined Addition of $\mathrm{Cu}$ and Aluminum Oxide Nanoparticles on Mechanical Properties and Microstructure of Al7Si-0.3Mg Alloy, Metallurgical and Materials Transactions A, v. 43A, pp. 738-746 (2012)

9. D.G. Mallapur, S.A. Kori, K.R. Udupa, Influence of Ti, B and Sr on the microstructure and mechanical properties of A356 alloy, J Mater. Sci., v. 46, pp. 1622-1627 (2011)

10. V.A. Shulov, A.N. Gromov, D.A. Teryaev, Yu.A. Perlovich, M.G. Isaenkova, and V.A. Fesenko, Texture formation in the surface layer of VT6 alloy targets irradiated by intense pulsed electron beams, Inorganic Materials: Applied Research, v. 8, pp. 387391 (2017)

11. K.C. Chan, C.L.Wang, K.F. Zhang, Low Temperature and High Strain Rate Superplasticity of Ni-1 mass\% SiC Nanocomposite, Materials Transactions: Japan Institute of Metals, v. 45(8), pp. 2558-2563 (2004)

12. A. V. Sotov, A. V. Agapovichev and V. G. Smelov, Experimental implementation of direct laser alloying, MATEC Web of Conferences, v. 129, 01060 (2017)

13. I.V. Ushakov, Method of mechanical testing of laser treated metallic glass by indenters with different geometry, Proceedings of SPIE - The International Society for Optical Engineering, P. 659714. DOI: 10.1117/12.726773 (2007)

14. A.A. Karabutov, A.Yu. Ivochkin, A.G. Kaptilniy, Phase transitions induced by nanosecond laser pulses in confined geometry (Nova Publishers, New-York, 2010)

15. V. Tangwarodomnukun, Overflow-assisted laser machining of titanium alloy: surface characteristics and temperature field modeling, The International Journal of Advanced Manufacturing, v. 88(1-4), pp. 147-158 (2017)

16. M. Purin, A. Zakharevich, and N. Gutareva, Mathematical modeling of melting during laser heating of metal plate, MATEC Web of Conferences, v. 110, 01070 (2017) 